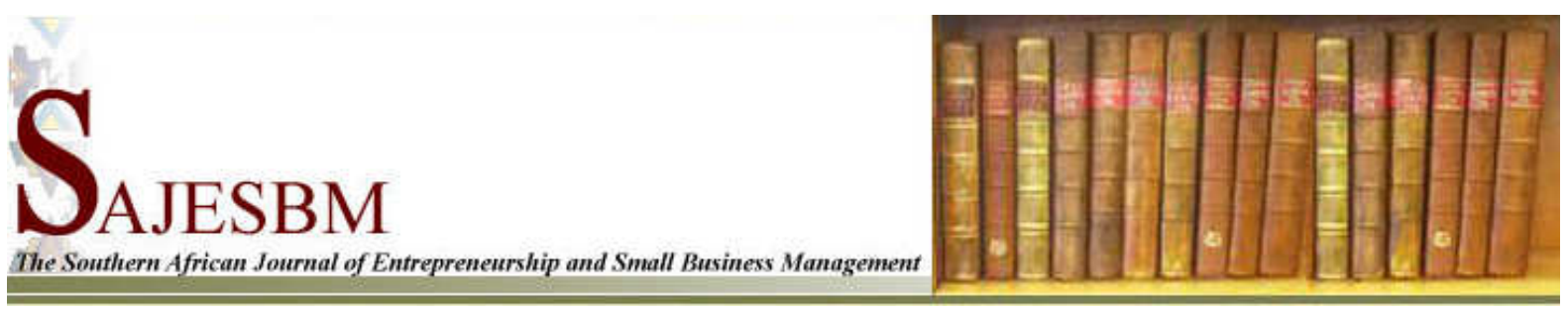

\title{
GUIDANCE FOR SMES WITH THE ADOPTION OF TECHNOLOGY: A CONCEPTUAL FRAMEWORK
}

\author{
AA Steyn * \\ University of Pretoria \\ Riana.steyn@up.ac.za \\ Phone: +2712420 3341 \\ Fax: +27123625287 \\ AC Leonard \\ University of Pretoria \\ Awie.leonard@up.ac.za
}

* To whom correspondence should be addressed.

\begin{abstract}
When starting up a new small or medium sized company, it is crucial to understand what the requirements are in terms of Information and communication technologies (ICT). Bentellis and Boufaïsa (2008) note that over the last twenty years the markets have been changing fast, which has led to the evolution of the business environment. In many instances companies cannot keep up with the change occurring in the ICT arena. Entering the market as a small competitor, you need to ensure that you implement ICT that will support your business strategies. This paper presents the findings of a qualitative research study done to determine how SMEs cope with the adoption of technology. The paper explores the typical problems and challenges faced by SMEs, within South Africa, with regard to ICT and propose a conceptual framework to support managers in their decision making on ICT implementation. As such, this framework supports them in choosing the relevant technology, as well as supporting them with the effective application of the chosen technologies.
\end{abstract}

\section{KEY WORDS}

Adoption, Information communications Technology (ICT), skills, small to medium organisations (SME), Technology

\section{INTRODUCTION}

According to Hilson (2003) SMEs are seen as the driving force of any economy. One has to realize the importance of the effective and successful implementation of ICT and what the impact thereof can be. However, due to the lack of resources, whether financial or human, SMEs tend to be reluctant to adopt ICT (Celuch, Murphy and Callaway, 2007). 
Section 1(15) of the National Small Business Act (102/1996) in South Africa where the research was done certain criteria have been developed to establish whether or not a business qualifies as a small business (criteria can be viewed in the Annexure). The act also defines small businesses within the South African context as a "distinct business entity, which is managed by an owner or more", and which satisfies the criteria as set out in the Annexure. When analysing these criteria, it becomes evident that within a South African context, an SME is classified as a business which has no more than 200 employees and has certain turnover criteria based on their industry. Thus, if a business has less than 200 employees but the revenue is more than the indicated value per industry, the argument of Brown and Kaewkitipong (2009) whereby SMEs are not only based on size, but also on complexity, becomes true. According to Fink and Disterer (2006) SMEs should be divided even further, namely micro, small and medium sized, with micro being one to five employees, small being six to 20 employees and medium between 20 and 500 employees. However, these numbers are used in a study on SMEs in Australia and Germany. Thus for this research paper, the assumption would be that SMEs are between 1 and 200 employees.

Kaynak, Tatoglu and Kula. (2005) note that SMEs can be seen as the power house of a country's economy. Kapurubandara and Lawson (2007) continue by stating that the development of the economy is affected by SMEs everywhere. Most governments have also realised the effect and impact small organisations have on a country's economy, as it leads to the growth of the economy as well as job and wealth creation (Oke, Burke, and Myers,. 2007). Hilson (2003) indicates that some of the main reasons why SMEs in Canada will not adopt IT are cost and the lack of time and expertise, as most of the IT skills are being swept up by the large firms. It seems as if the skills acquired by students from tertiary institutions are highly specialized and thus the students feel that they could be "better utilized" within larger organisations. The lack of resources, both financial and human, is even bigger in developing countries, as indicated by Ellis and van Belle (2009).

When starting up a new organisation, or trying to adapt to the rapid rate of IT evolution experienced all over the world, it is crucial to understand what the requirements are in terms of Information and communication technologies (ICT).

Wixom and Todd (2005) mention the need to develop a set of characteristics which can be applied across a range of systems in order to integrate user perceptions and IT adoption. There is a need to identify what has been done to date with regard to IT adoption models and whether these models can, in some way, be combined to develop a standard conceptual framework to be used by SMEs and extended into future studies as a guideline for any organisation's IT strategy.

\section{LITERATURE REVIEW}

\section{SMEs and their dependency on ICT}

For SMEs staying ahead and maintaining a competitive advantage becomes critical for survival. Yu (2001) notes that the origins of small enterprises' competitive advantages have not yet been critically examined. However, the evolution of firms have recently expanded to such an extent that it opens up a whole new dimension to be examined from a business enterprise viewpoint.

Yu (2001) identified two distinctive assets of small firms, namely the access to a simple capital structure and entrepreneurship. Small firms also have the capability to produce or deliver within a limited time span, as they are more flexible than larger firms to adapt to changes. Chibelushi and Costello (2009) also confirm this by saying that SMEs are more flexible, innovative and can respond to changes in their environments much faster. Based on 
the rapid rate of IT evolution, IT becomes a "tool" to gain the upper hand in the industry and ensures it doesn't become just another entry on a timeline going nowhere.

\section{Technology characteristics for the SME environment}

There is a magnitude of technologies available in the market, and one quickly realizes that there are such a large number of products available, and that exploring all the literature would be a never ending quest.

Without a professional opinion in terms of what technology to buy and what not to buy, quality decision making by the management of SME's stays a challenge. Decisions by management without professional support can have a devastating influence on the bottom line (Dyerson, Harindranath, and Barnes, 2009) and will either enhance competitive advantage or start a slow downward spiral towards business closure.

The various levels of technology available and where SMEs fit in should be considered at this point. Kendall \& Kendall, 2011:30 used figure 1 to identify the various levels of systems or applications within an organisation.

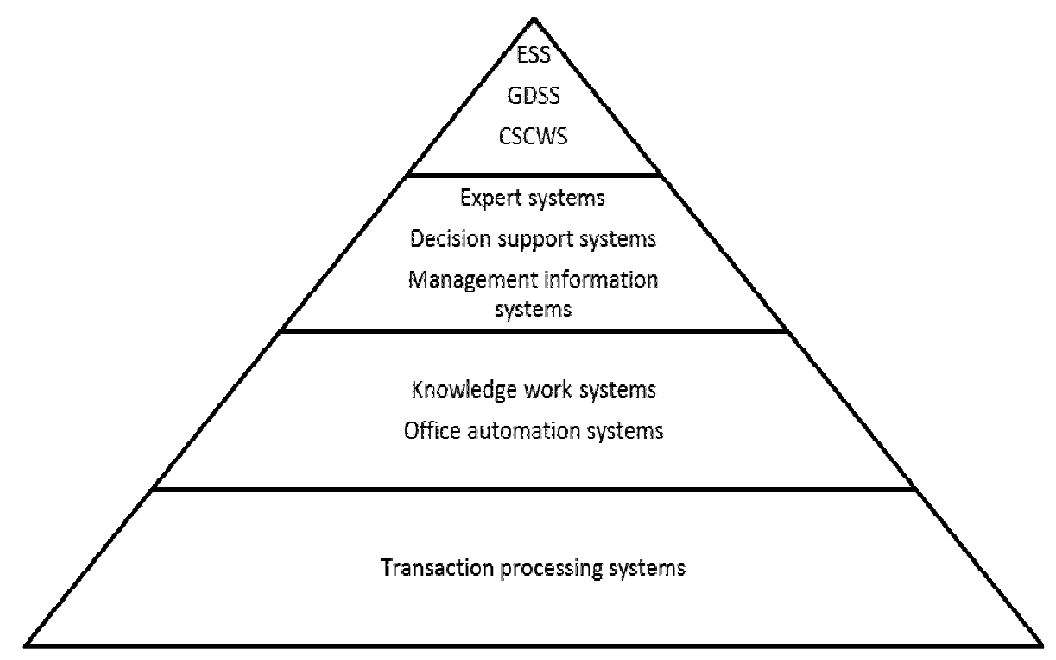

Figure 1: Different system levels (Kendall \& Kendall, 2011:30)

With figure 1 in mind, the following arguments help one to understand that most SMEs are really applying information technology on the lower levels and in the majority of cases not higher than the MIS level of the figure.

From the research of Chibelushi and Costello (2009) it emerged that most owners of SMEs firstly seek advice on what type of ICT to adopt from friends, relatives or other SME owners. Due to these owners not having adequate knowledge of IT, they do not necessarily adopt the correct ICT, if any at all. However, Dyerson et al. (2009) conducted a study on about 519 SMEs in the UK, and they found that the largest area where SMEs will start to gain advice from are IT consultants and secondly from personal sources such as family and friends. This does not make the fact that SMEs tend to look for sources outside the company worthless, but rather indicate their lack of internal resources which the SME might have available.

According to Dyerson et al. (2009) the following technologies are the ones mostly used by SMEs, in no particular order:

- Company Website

- Email

- Extranet or electronic data interchange

- Groupware (E.g. Lotus Notes) 
- Internet

- Intranet

- Computer network

- Video/Audio conferencing

- Wireless access

However, to identify the specific software that a SME will need is almost impossible and these are mere guidelines to indicate which focus points SMEs will consider when adopting a specific ICT.

\section{IT Strategy - when does IT become relevant?}

Strategic planning and skills availability within an SME are two of the most important aspects when one begins to investigate the adoption of ICT. One has to realise where you want your business to go within the IT environment to ensure effective management and cost-effective solutions.

Sandberg and Vinberg (2000) note that for SMEs to survive and grow in the future, it becomes a matter of strategic importance to adopt information technology. When developing a tool to "ease" the workload of the employees, it is also critical to involve these employees to ensure that the strategies as well as the tools are relevant to their occupation, to improve productivity.

Both Goldstuck (2009) and Nel (2009) discuss the findings of the World Wide Worx report which had interviews with about 1000 SME decision-makers. It became clear that most of the key staff, or in some cases all the staff, are out of the office at least once a day visiting customers. As a result of this, SMEs are more concerned with the type of mobile device, such as the cell phone and laptop which they can use while on the go. Nel (2009) mentions that $24 \%$ of key personnel work "outside" the office and $29 \%$ have to leave the office at least twice a day. The fact that most technologies today allow for mobility has become a great advantage and it creates the ability for these personnel to move around more freely.

\section{IT adoption models}

In this section three adoption models are introduced followed by brief explanations of how these models are being used in certain areas of research. These models were chosen due to their impact on the social aspects of IT adoption, as well as the fact that the unified model already contains most of the important aspects of the eight models which focus on the social aspect of adoption (Venkatesh, Morris, Davis and Davis., 2003). Another reason why only these three models were identified, is due to the statement Bagozzi (2007) made where he said that adoption models are reaching a point of chaos and each new model leads to new fragmentations of already created models. These models were analyzed to find the most appropriate one. The model's characteristics will be used to build the conceptual framework for ICT adoption by SMEs within a South African context.

Chibelushi and Costello (2009) argue that without a clear understanding of the model and scope of adoption, the result could be that the investment in ICT does not deliver any value. As mentioned by Bhattacherjee and Sanford (2006), Rogers (2005) said "IT acceptance is fundamentally a problem of social influence". Handy, Whiddett, and Hunter (2001) state that one has to be careful to view the technical and social side of information systems isolated from each other. Thus, there is a noteworthy interaction between humans and the implementation and success of ICT. 
Table 1: List of IT acceptance models

\begin{tabular}{|l|l|}
\hline MODEL & ABBREVIATION \\
\hline Elaboration Likelihood model & ELM \\
\hline Technology Acceptance model & TAM \\
\hline $\begin{array}{l}\text { Unified theory of acceptance and use of } \\
\text { Technology }\end{array}$ & UTAUT \\
\hline
\end{tabular}

\section{Elaboration likelihood model}

Fadel, Durcikova and Cha (2008) indicate that ELM is used to account for "variations in information influence across individuals and contexts". Thus, it realises the importance of individual perceptions and how these perceptions are formed. They continue by stating that it is a way in which the utility of information is judged through cognitive elaboration. Bhattacherjee and Sanford (2006) note that there are two routes which influence the attitudes amongst individuals. Bhattacherjee and Sanford (2006) further state that the two core drivers of the acceptance of IT are attitude and perceived usefulness. On the other hand, Sussman and Siegal (2003) identify ability and motivation as influencing factors of elaboration.

Fadel et al. (2008) mention that the central route refers to argument quality and the peripheral route refers to source credibility. While explaining the Innovative diffusion theory, Bhattacherjee and Sanford (2006) mention that adoption is viewed as a one-time decision and the long time effects or post-adoption effects are ignored. However, it is stated that the central route of ELM is more stable in terms of the influence effects than the peripheral route.

Below are some of the main categories which emerged from the studies of Bhattacherjee and Sanford (2006):

- Relevance $=$ Motivation degree

- Expert user level = Effort degree required

- Ease of use

- Influence = Decreases over time

Bhattacherjee and Sanford (2006) identify seven constructs that influence the adoption of technology. They are perceived usefulness, attitude, acceptance intention (", argument quality ("persuasive strength of arguments embedded in an informational message", Bhattacherjee \& Sanford, 2006:811), source credibility ("extent to which an information source is perceived to be believable, competent, and trustworthy by information recipients", Bhattacherjee \& Sanford, 2006:811), and user expertise and job relevance. Each one of these characteristics and constructs were analysed to identify which will become relevant in constructing the conceptual framework.

\section{Technology acceptance model}

Reimenschneider, Harrison and Mykytyn (2003) note that TAM is the model most likely to be used for IT adoption in small businesses, due to the social approval of this model. In this regard Bagozzi (2007) identifies TAM as the leader model of technology acceptance for more than two decades.

Lu, Yu, Liu and Yao (2003) argue that TAM focuses on the "consciously intended behaviours". In other words attitudes lead to intentions, which lead to behaviours. The primary "belief" of TAM is that all IT adoption relates to ease of use and usefulness.

They continue by stating that attitude will be the deciding factor of the intention to adopt a specific system. However, according to a study conducted by World Wide Worx (Goldstuck, 
2009) $80 \%$ of South Africa's SMEs noted that ease of use is an important criteria for adopting wireless technology, with $79 \%$ also noting quality as an important aspect. Continuing with the findings of the study, $74 \%$ noted that maintenance is important and $72 \%$ chose reliability. Price was only ranked as the $5^{\text {th }}$ most important aspect of why SMEs will adopt wireless technology. These findings are a clear indication that certain parts of TAM could be used as the basis for technology adoption within SMEs such as ease of use. Ease of use is one of TAM's measurements which is rated as the number one reason for adoption within the South African market.

On the other hand, TAM is a model used to explain computer usage. Mehrtens, Cragg and Mills (2001) identify three factors which ultimately influence or affect the adoption of the Internet by small firms. These factors are perceived benefits, organisational readiness and external pressures. One thing to keep in mind at this stage is that the research paper investigates SMEs which, as mentioned earlier, usually involve one owner who tends to be the decision-maker. Yu (2001) also states that the owner's perceptions are mostly the cause of the sluggishness of information technology adoption. Dyerson et al. (2009) however indicate that very few SMEs adopt technology as a result of external pressures, but rather to gain a competitive advantage, to enhance operational efficiency, as well as to improve their services to their customers and to satisfy their staff. As mentioned earlier, two of the issues faced by SMEs during IT adoption are attitudes, as well as customer behaviour (Chibelushi and Costello, 2009).

Reimenschneider et al. (2003) continue by acknowledging that small businesses face problems when implementing IT in terms of the adoption of IT and the use thereof.

Lu et al. (2003) continue by saying that the adoption of Wireless Internet via a mobile device is strongly influenced by prior experience as well as the adopters' level of innovation. They argue that the more innovative a person is, the more one tries new things and should then develop more positive perceptions towards new technology.

\section{Unified theory of acceptance and use of technology}

Venkatesh et al. (2003) conducted a study to create a unified acceptance model which took eight prominent adoption models into consideration and proposed the UTAUT model. They did however acknowledge that the model still requires some additional research but the foundations of UTAUT will now be discussed. Models such as "the theory of reasoned action, the technology acceptance model, the motivational model, theory of planned behaviour, a model combining the technology acceptance model and the theory of planned behaviour, the model of PC utilization, the innovation diffusion theory and the social cognitive theory" were compared - Venkatesh et al. (2003),

After conducting intensive studies into the eight different research models, there seem to be seven constructs which have a direct influence on the intention of usage in the individual models. However, Venkatesh et al. (2003) have identified four constructs or building blocks which play a considerable role in determining user acceptance as well as behaviour. These four constructs or building blocks are: performance expectance, effort expectancy, social influence and facilitating conditions.

\section{Framework building blocks}

Having drawn a mind-map of all the characteristics of these three models, it became evident that the relationships between the characteristics are rather strong. As identified by Korunka, Weiss and Zauchner (1997), organisational flexibility and competitiveness increase through the use of information technology and can be used as a basis to explain the urgency of adoption of these systems. 
Table 2 indicates all the main characteristics which emerged from the models as well as the literature in the form of building blocks.

\section{Table 2. Building blocks}

\begin{tabular}{|c|c|c|c|c|c|c|c|c|c|}
\hline Theme or & \multicolumn{8}{|c|}{ Building Blocks } & \multirow{2}{*}{$\begin{array}{l}\text { Resources } \\
\text { Fadel et al. (2008:2); } \\
\text { Bhattacherjee \& Sanford } \\
(2006: 807) ; \text { Sussman \& Siegal } \\
(2003: 52)\end{array}$} \\
\hline ELM & Attitude & $\begin{array}{l}\text { Perceived } \\
\text { usefulness }\end{array}$ & $\begin{array}{l}\text { Job rele- } \\
\text { vance }\end{array}$ & $\begin{array}{l}\text { Source } \\
\text { credibility }\end{array}$ & Intention & $\begin{array}{l}\text { Job } \\
\text { relevance }\end{array}$ & $\begin{array}{l}\text { Argument } \\
\text { quality }\end{array}$ & Expertise & \\
\hline TAM & Attitude & $\begin{array}{l}\text { Perceived } \\
\text { usefulness }\end{array}$ & Job fit & $\begin{array}{l}\text { External } \\
\text { pressures }\end{array}$ & Intention & Job fit & & & $\begin{array}{l}\text { Reimenschneider et al. } \\
(2003: 271) ; \text { Lu et al. } \\
(2003: 207) ; \text { Bagozzi (2007:244); } \\
\text { Yu (2001:189); Dyerson et al. } \\
(2009: 42)\end{array}$ \\
\hline UTAUT & & $\begin{array}{l}\text { Usefulness } \\
\text { / Ease of } \\
\text { use }\end{array}$ & Job fit & Social factors & & Job fit & Expectancy & & Venkatesh et al. (2003:425) \\
\hline $\begin{array}{l}\text { Mobile } \\
\text { Devices }\end{array}$ & & $\begin{array}{l}\text { Easy to } \\
\text { use / } \\
\text { Useful }\end{array}$ & & & & & & Availability & Hart \& Hannan (2004:201) \\
\hline $\begin{array}{l}\text { Successful } \\
\text { projects }\end{array}$ & & & & $\begin{array}{l}\text { User \& } \\
\text { Management } \\
\text { involvement }\end{array}$ & & & $\begin{array}{l}\text { Expecta- } \\
\text { tion }\end{array}$ & & Liebowitz (1999:66) \\
\hline Challenges & Attitude & & & & $\begin{array}{l}\text { Customer } \\
\text { behaviour }\end{array}$ & & & $\begin{array}{l}\text { Technology } \\
\text { changes }\end{array}$ & Chibelushi \& Costelle (200:212) \\
\hline
\end{tabular}


When looking at the building blocks, it is evident that all three of the models place a high emphasis on the social aspects of IT adoption. During the adoption of IT, it seems as if a high emphasis is placed on the ease of use and usefulness of the technology being adopted, as well as the attitude of the end users of this technology, as attitude will lead to intention which will lead to a specific action by the user. Job fit is also an aspect which emerged throughout all three models, including compatibility with a user's job functions. External influence, whether it is via a friend or via an expert, also seems to be a determinant of the adoption of certain types of technology. These would thus be the first characteristics which will be used to build the conceptual framework for this research paper.

\section{RESEARCH METHODOLOGY}

In this research study we followed an interpretive research approach. Myers (2009) mentions that interpretive research assumes that knowledge is gained, or reality is accessed, by the use of social structures such as language and shared meanings. He continues by saying that interpretive research focuses on human sense-making and that the only way to make sense of a subject matter is to investigate it from the inside out, rather than standing on the outside and trying to see what is happening. Klein and Myers (1999) confirm the impact of the social context of an organisation on interpretive research, and that interpretive research has the potential to create valuable insight into organisational systems and processes. Due to the fact that this paper will be based on qualitative data gathering, which involves discussions with the research participants, the researcher had to take time to understand the business before certain assumptions could be made and the context wrongfully interpreted.

Qualitative research has been a popular approach in various research studies (Myers and Newman, 2007; Myers, 2009). Qualitative interviewing, if used correctly, could be a powerful tool in a research environment. But even though most researchers use the interviewing process as their means of data gathering, it is also loaded with difficulties and shortcomings. Myers (2009) states that an interview allows the researcher to "gather rich data from people in various roles and situations", thus focusing on the social aspect of the interviewee. As was mentioned earlier, it is important to realise the SMEs are focusing on the social aspect of an organisation, because qualitative research is a technique to gather data from people.

\section{DATA GATHERING}

The target research population is SMEs within a South African context. The research identified ten SMEs based in various towns to identify what their experiences were when starting their business, and how they experience the use and benefits of ICT. Four of the SMEs interviewed, operate their business in a more rural environment and this also provided an understanding of services and support available in these areas. (Of these towns 6 are in Pretoria, one based in Kempton Park, two based in Witbank and one based in Middelburg, Mpumalanga.)

By conducting interviews with this broad spectrum of SMEs, the researchers gained a better understanding of the needs of South African SMEs when adopting ICT, and also whether the differences between urban and more rural based SMEs are at all significant.

During the interviews, the researchers made notes and the interviews were recorded by using a digital recording device. Once all the interviews were conducted, the recordings were transcribed and common themes which have emerged were identified. The contents of the interviews were summarized and each question asked during the interview was analyzed in order to determine which aspects of ICT are important for SMEs.

\section{DATA ANALYSIS}

The data was analysed by using the four constructs of Fink and Disterer (2006:611). Each company's social networks are discussed by using the four constructs. This is sanctioned by 
Myers (2009:39) who argues that it is crucial to understand the context of the business, as this defines the relevance of data. An example of one of the companies' classification can be viewed in the Annexure.

Fink and Disterer (2006) realise that determining IT adoption within SMEs, is influenced by the social aspect of IT and how IT affects the social aspects of the organisation. Fink and Disterer (2006) introduced four constructs whereby social networks can be described. These four constructs are:

Interaction: users use ICT to interact with others within their work environment. Thus the information and resources are being "mobilised as people engage with affiliated organisations."

Environment: The organisational needs are identified in order to recognise the environment by using ICT as well as what the organisational industry focus is.

Affiliations: Social networks being created by people with their computers, within the organisation as well as in the industry within which they operate.

Identities: Identify the kind of staff employed as well as acknowledgement of the members within the organisation either as individuals or as collective entities.

After each company's background and context had been analysed, the researchers could form a better idea of why certain answers were provided by the research participants on certain questions and all the data was analysed. The interview questions could be divided into three focus groups which helped to classify and clarify the interview responses across all the various interviews. These three groups are:

1. Employees, their skill levels as well as training provided. Communication between SME, personnel and customers, and the impact of their competitors in the market.

2. Current ICT infrastructure in place as well as support and service providers currently being used.

3. Security and the possibility of a business continuity plan are deciding factors for the SME when considering investment in ICT, future goals and possible wish lists that the SMEs might have for their ICT.

Each interview question was constructed by looking at themes and aspects which emerged from the literature review.

As mentioned earlier, SMEs for this study include anything from 1 to 200 employees. However, during the interviews the researcher realized that SMEs have to be broken down even further on account of their size, as was done by Fink and Disterer (2006). They divided SMEs into micro, small and medium sized, with micro consisting of one to five employees, small of six to 20 employees and medium of 20 to 500 employees. However, for this study, the classification will be as follows: micro one to 5 employees, small 6 to 30 employees and medium 31 to 200 employees and large, even though not part of SMEs, 201 to unlimited according to the South African classification as discussed earlier.

The research participants emphasised reliability of the technology as they specifically indicated reliable battery life for mobile devices, reliable information being produced etc. Other aspects such as cost, upgrading and compatibility were also mentioned. Cost is relevant to the specific technology, as one cannot get away from the cost factor in any technology. All of the research participants indicated that the cost of an article will determine whether they will invest in it or not. Cost is noted as important but inevitable and thus will not be included in the framework. Upgrading can be seen as part of support which in turn forms part of the external influence characteristics. Compatibility forms part of reliability as well as usefulness, and will thus not be mentioned again in the framework. 


\section{CONCEPTUAL FRAMEWORK}

There seems to be a magnitude of advice and data available surrounding the adoption of IT. As was discussed earlier, there are specific adoption models which highlight the main characteristics of IT adoption for SMEs. There is also an endless wave of technology and ways in which an SME can adopt IT not only within South Africa, but throughout the world. The conceptual framework serves as a guide to help one to make sense of a magnitude of concepts as indicated by Smeyers (2008).

In the rest of this section a conceptual framework is developed, based on the different interviews as well as what was found in the literature. Each sub-section discusses the content of the different building blocks of the framework.

\section{Relevant IT}

Micro: As was identified during the interviews, micro SMEs realise that they cannot function without IT, but they do not necessarily require high-level state of the art technology. All of these companies have emails, access to the Internet as well as a Telkom line. They seldom have a fixed network infrastructure and thus they will tend to use $3 G$ devices to connect to the Internet and emails, thus ensuring mobility is achieved. It seems as if a financial package is not always required, except for those who do see the need for financial transactions. QuickBooks accounting is seen as a simple and easy way to adopt for their "simple" business operations. What did emerge, though, is that backups of data are not always a priority for these companies. They will however have to start implementing a procedure whereby data is stored on a backup device and stored off-site to ensure confidentiality firstly and secondly, to familiarise themselves with a business continuity plan. Though not formal, this is the first step towards achieving this goal. An updated anti-virus system is also required to protect their PCs or laptops, as recommended by Beck (2007).

Small: When companies expand and become part of the small group, everything relevant to micro companies is included but small companies will tend to focus more on Pastel rather than QuickBooks. As commented by Company $\mathrm{H}$, this is due to the fact that most accountants are familiar with Pastel, as they are trained in Pastel and thus there is no extra cost involved in training. At the small level, skills development also starts to play a role. Skills development might not necessarily involve IT skills, although small companies start to realise the benefit and importance of outsourcing their IT functions and that IT could assist them in their business needs. Small companies will also start investing in websites mostly for marketing purposes, as well as network infrastructures to connect the employees with one another. It is also at this point where the need arises for some kind of operational system to ensure productivity and accurate information for management decision-making. Here the TPS systems of Kendall \& Kendall, 2011:30 being the first level of information systems, come into play where they say that the core business functions and transactions are now being recorded by using operational systems.

Medium: Medium companies have the same requirements as micro and small companies. However, they realise the need to employ in-house IT resources. At this stage a company starts to introduce more advanced operational systems such as enterprise resource systems, especially on the financial side of the business. The need for accurate information for decision making now starts to influence IT decisions thus relating back to Kendall \& Kendall, 2011:30 MIS systems. These systems tend to become more expensive and thus the small and micro companies do not venture into them.

Large: Everything which emerged from micro, small and medium companies but with additional add-ons are required by large companies. The large company has already invested into IT and infrastructure; they now start to look at what the world wide IT trends are 
and which of these trends can be invested in to ensure that maximum competitive advantage is reached. As this study does not focus on the large organisations, this part will only serve as an introduction for future research to expand the framework introduced.

Thus, the relevance of IT to the size of the company can be introduced as follows:

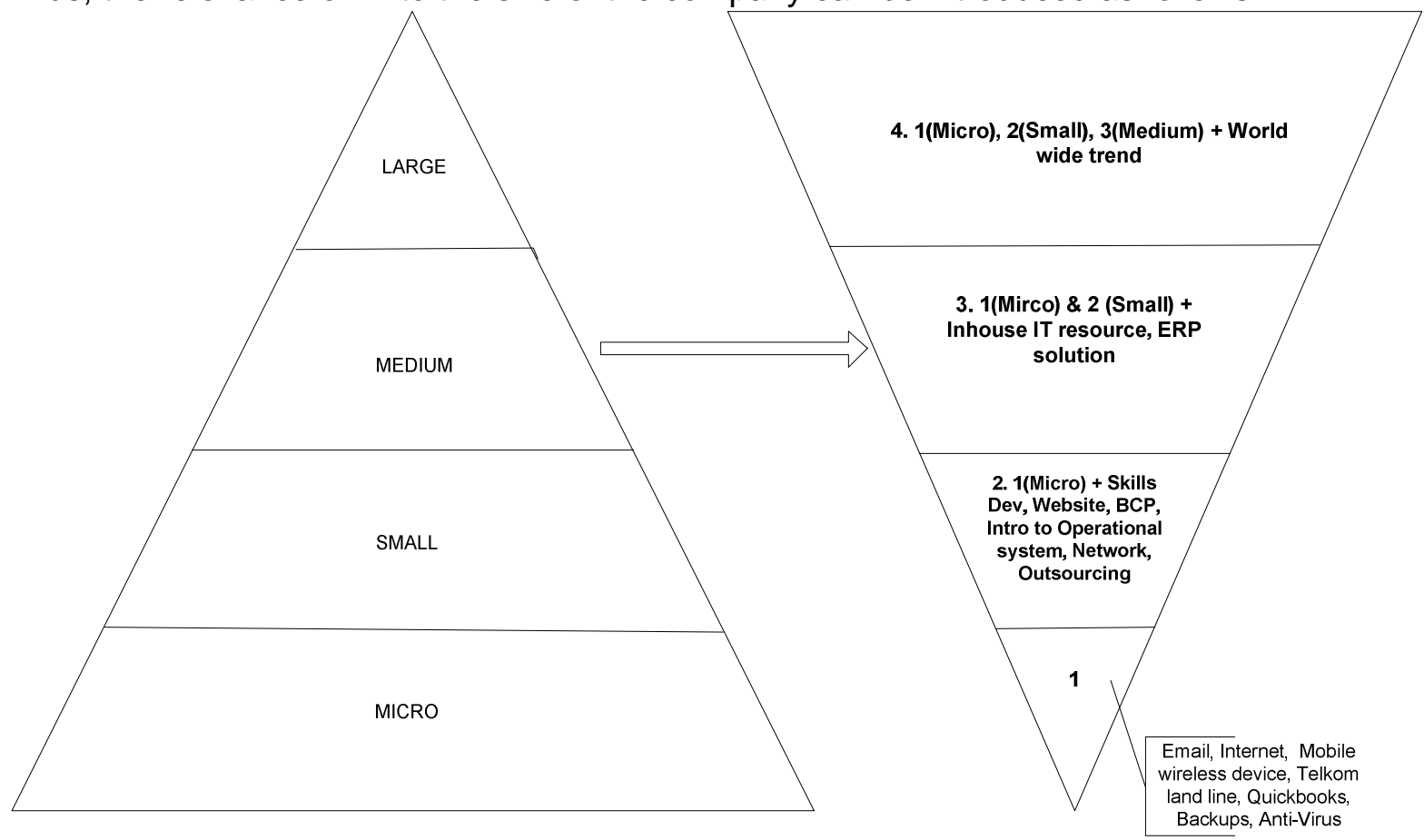

Figure 2: IT relevance framework

From figure 2, one can notice the correlation between the size of the organisation and their level of IT adoption, as discussed above.

\section{IT decision characteristics}

During the research study, various adoption approaches of IT were discussed, but which of these techniques suits the SME adoption framework the best? As indicated earlier the following characteristics will be taken from the adoption models:

- Ease of use

- Usefulness of the technology

- Attitude of the users

- Job fit

- External influences, whether it is via a friend or via an expert, also seem to be a determinant of the adoption of certain types of technology. External influences also relate to the credibility of the source providing the external influence.

Referring back to the data analysis section, the only additional characteristic that will be added to the above mentioned characteristics will be reliability.

These characteristics will be displayed at the bottom of the framework as the SMEs need to remember them when choosing the best technology to invest in.

\section{Organisational strategy}

Once the organisational strategy is known, one can incorporate the business processes which will lead to the IT strategy, thus ensuring that the adoption of IT within the company becomes integrated with the business' objectives. Thus the company's strategy will become 
the glue which assists an SME with adoption and future growth and will be displayed on the right-hand side of the conceptual framework.

Organisational strategies include the IT strategy. What is emerging, is that strategies need to be in place so that the SMEs know what they want to achieve, and based on these strategies and goals, ICT needs to be decided upon, thus providing the necessary glue to build the company's structures and IT requirements.

\section{Combined framework}

Figure 3 illustrates, combined in one framework, all the concepts which can be used by SMEs to adopt IT from a South African point of view, based on the size of the company. All of the building blocks of the framework are interlinked in order to ensure that the SME knows what to look for when choosing IT to invest in.

As stated earlier, this conceptual framework is only a guide to help one to make sense of a magnitude of concepts, as indicated by Smeyers (2008). It does not mean that micro cannot adopt one of the concepts of the small companies. Therefore, the role of this framework is to support personnel of SMEs in their decision making with regard to the use of ICT.

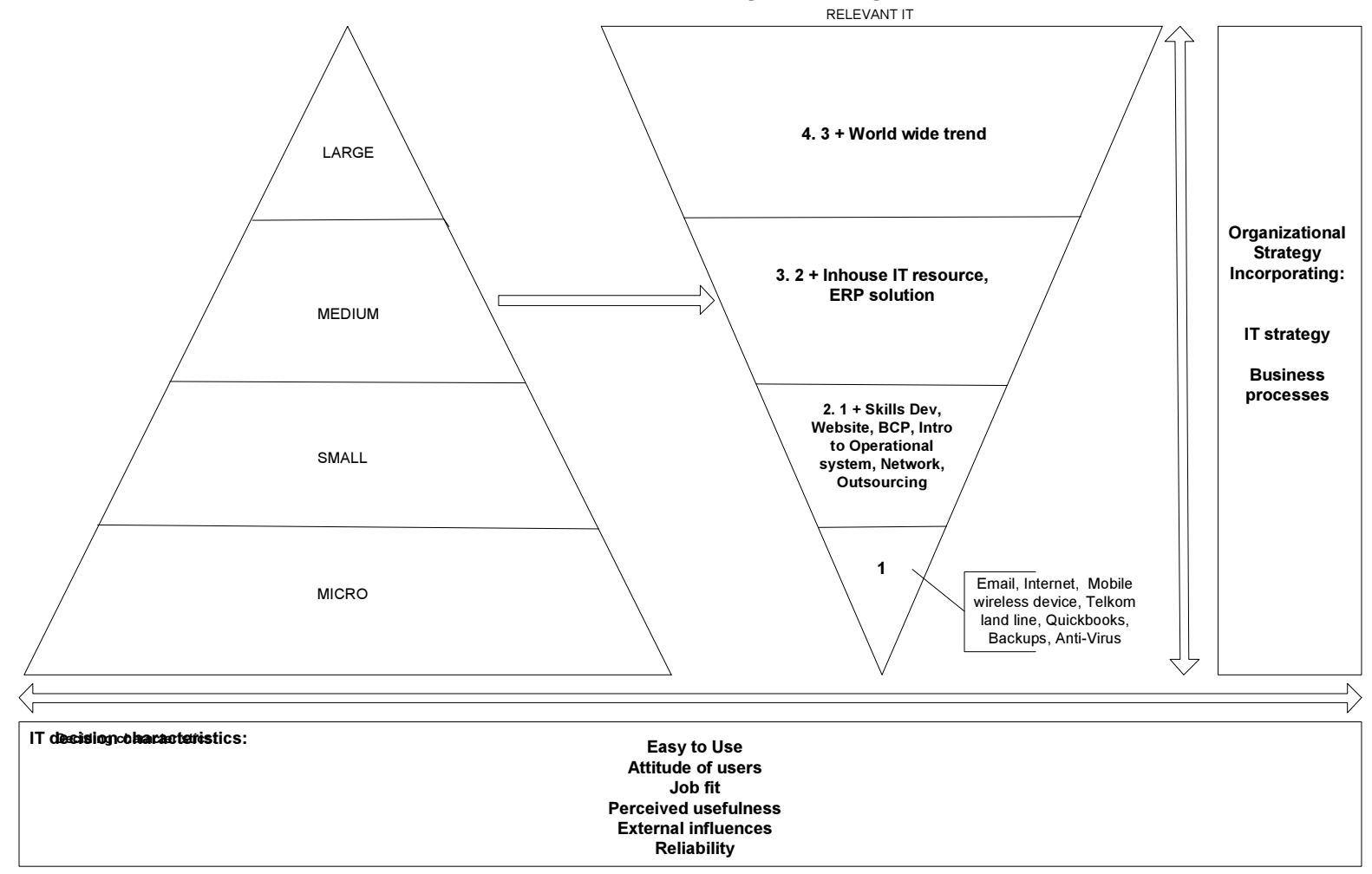

Figure 3: Conceptual framework for guiding SMEs in adoption of IT from a South African point of view

\section{Recommendations}

What emerged from this study, though, is the impact of the social presence relating to decision-making within SMEs. Thus it is recommended that one engages with the employees within your organisation, as it allows for multiple inputs from these employees which could guide you in your decision-making.

\section{Future research}

Throughout this study, suggestions for potential future research have emerged. There is a need to develop guidelines assisting the decision-makers of an organisation to outsource or 
not to outsource. One also has to investigate the reason why some larger companies prefer to do in-house training and if large companies encourage people to enrich themselves through continuous studies or training, which of these companies will carry the cost.

Furthermore, the recommended framework was not tested during this study. This could also be done in future studies.

\section{CONCLUSION}

The research study explores the typical problems and challenges faced by SMEs with regard to ICT adoption. The study highlights the uncertainty of SME managers with regard to the general use of contemporary technology, and that they are in many cases, as far as decision making is concerned, in the hands of people who do not care for their businesses. In many cases they do not know what to do and because of a lack of skills and information, they sometimes make critically wrong decisions with the adoption approach.

In this study we propose a conceptual framework to support managers in their decision making with regard to ICT implementation. This conceptual framework, we argue, can be of great support to SME's when they need to deal with difficult decisions as far as the adoption of ICT equipment and or strategies are concerned. Although the empirical research was done in the South African business environment, we argue that this adoption model could be of great value to SME's in other parts of the world with similar conditions than those in South-Africa. 


\section{REFERENCES}

Bagozzi, R.P. 2007. 'The Legacy of the Technology Acceptance Model and a Proposal for a Paradigm Shift', Journal of the Association for Information Systems, 8(4), pp. 244-254.

Beck, R. 2007. 'Business need business continuity plans now more than ever', Focus, 12.

Bentellis, A. \& Boufaïsa, Z. 2008. 'Conceptual Method for flexibility business process modelling', International Journal of Human and Social Science, 2(3), pp. 139-143.

Bhattacherjee, A. \& Sanford, C. 2006. 'Influence processes for information technology acceptance: an elaboration likelihood model', MIS Quarterly, 30(4), pp. 805-825.

Billings, J. 2009. 'Advice is like caster oil, easy enough to give but dreadful uneasy to take.' [Online] Available: http://cookingintheory.blogspot.com/2009/03/advice-is-like-castor-oileasy-enough.html [Accessed: 4 March 2010].

Brown D.H \& Kaewkitipong, L. 2009. 'Relative size and complexity: e-business use in small and medium sized tourism enterprise in Thailand', Journal of Enterprise Information Management, 22(1/2), pp. 212-231.

Celuch, K., Murphy G.B. \& Callaway, S.K. 2007. 'More bang for your bucks: Small firms and the importance of information technology capabilities and strategic flexibility', Journal of High Technology Management Research, 17, pp. 187-197.

Chibelushi, C. \& Costello, P. 2009. 'Challenges facing the W.Midlands ICT-oriented SME's', Journal of Small Business and Enterprise Development, 16(2), pp. 210-239.

Coff, R.W. \& Laverty, K.J. 2001. 'Roadblocks to competitive advantage: How organizational constraints and individual decision biases hinder investments in strategic assets', Journal of High Technology Management Research, 12, pp. 1-24.

Department of Trade and Industry: Annual review of small business in South Africa, 2005 2007. 2009. [Online] Available: http://www.dti.gov.za/offerings/offeringgroup.asp? offeringgroupid=22 [Accessed: 9 March 2010].

Department of Trade and Industry: South Africa. 1996. National Small business act, No. 102 of 1996:1-16 [Online] Available: http://www.thedti.gov.za/smme/act.pdf [Accessed: 21 August 2009].

Diefenbach. T. 2007. 'The managerialistic ideology of organisational change management', Journal of Organizational Change Management, 20(1), pp. 126-144.

Dyerson, R., Harindranath, G. \& Barnes, D. 2009. 'National survey of SMEs' use of IT in four sectors', The Electronic Journal Information Systems Evaluation, 12(1), pp. 39-50.

Ellis, J. \& van Belle, J.P. 2009. Open Source Software Adoption by South African MSEs: Barriers and Enablers. Proceedings of the 2009 Annual Conference of the Southern African Computer Lecturers' Association, Eastern Cape, South Africa, 29 June - 1 July 2009:41-49.

Fadel, K.J., Durcikova, A. \& Cha, H.S. 2008. 'Elaboration likelihood in knowledge management: a Model and experimental test', Proceedings of the $41^{\text {st }}$ Hawaii International Conference on System Sciences - 2008, pp. 1-10.

Fink, D. \& Disterer, G. 2006. 'International case studies: To what extend is ICT infused into operations of SMEs?', Journal of Enterprise Information Management, 19(6), pp. 608-624.

Goldstuck, A. 2009. 'Make it easy: SMEs want mobility simplicity', iWeek, 206, pp. 11.

Handy, J., Whiddett, R. \& Hunter, I. 2001. 'A technology acceptance model for interorganisational electronic medical records', Australian Journal of Information Systems, 9(1), pp. 39-50. 
Hart, J. \& Hannan, M. 2004. 'The future of mobile technology and mobile wireless computing', Campus-Wide Information Systems, 21(5), pp. 201-204.

Hilson, G. 2003. 'Canadian SME e-business growth stalled by a lack of IT skills: Report', Computing Canada, 23 May, pp. 1.

Jackson, M. \& Sloane, A. 2009. 'Organisation profiling and the adoption of ICT: e-Commerce in the UK construction industry', The Electronic Journal Information Systems Evaluation, 12(1), pp. 67-74.

Kapurubandara, M. \& Lawson, R. 2007. 'SMEs in developing countries need support to address the challenges of adopting e-commerce technologies', Proceedings of the $20^{\text {th }}$ Bled eConference eMergence: Merging and emerging technologies, processes and institutions, 4 -6 June, pp. $485-498$.

Kaynak, E., Tatoglu, E. \& Kula, V. 2005. 'An analysis of the factors affecting the adoption of electronic commerce by SMEs: Evidence from an emerging market', International Marketing Review, 22(6), pp. 623-640.

Kendall, K.E. \& Kendall, J.E. 2011. Systems analysis and design, $8^{\text {th }}$ edition. Pearson Education: Prentice Hall

Klein, H.K. \& Myers, M.D. 1999. 'A set of principles for conducting and evaluating interpretive field studies in information systems', MIS Quarterly, 23(1), pp. 67-88.

Korunka, C., Weiss, A. \& Zauchner, S. 1997. 'An interview study of 'continuous' implementations of information technology', Behaviour and information technology, 16(1), pp. 11-24.

Liebowitz, J. 1999. 'A look at why information systems fail', Kybernetes, 28(1), pp. 61-67.

Lu, J., Yu, C., Liu, C. \& Yao, J.E. 2003. 'Technology acceptance model for wireless Internet', Internet research: Electronic networking applications and policy, 13(3), pp. 206-222.

Mehrtens, J., Cragg, P.B. \& Mills, A.M. 2001. 'A model of Internet adoption by SMEs', Information and management, 39, pp. 165-176.

Myers, M.D. and Newman, M. 2007. 'The qualitative interview in IS research: Examining the craft', Information and Organization, 17, pp. 2-26.

Myers, M. D. 2009. Qualitative research in business and management. London EC1Y 1SP, SAGE Publications Ltd.

Nel, C. 2009. 'KMO's kyk na slimfone', Sake24, 15 September 2009. [Online] Available: http://www.sake24.com/articles/default/display_article.aspx?Channel=News_IT\&Articleld=6104_2553225\&IsColumnistStory=False [Accessed: 3 November 2009].

Oke, A., Burke, G. \& Myers, A. 2007. 'Innovation types and performance in growing UK SMEs', International Journal of Operations \& Production Management, 27(7), pp. 735-753.

Pati, N. \& Desai, M.S. 2005. 'Conceptualizing strategic issues in information technology outsourcing', Information Management and Computer Security, 13(4), pp. 281-296.

Rantapuska, T \& Ihanainen, O. 2008. 'Knowledge use in ICT investment decision making of SMEs', Journal of Enterprise Information Management, 21(6), pp. 585-596.

Reimenschneider C.K., Harrison, D.A. \& Mykytyn, P.P. 2003. 'Understanding it adoption in small business: integrating current theories', Information \& management, 40, pp. 269-285.

Sandberg, K.W. \& Vinberg, S. 2000. 'Information technology and learning strategies in small enterprises', Behaviour and Information Technology, 19(3), pp. 221-227.

Smeyers, P. 2008. Qualitative and quantitative research methods: old wine in new bottles? On understanding and interpreting educational phenomena. Paedagogical Historica, 
44(6):691-705.

[Online]

Availbale: http://www.informaworld.com/smpp/title content=t713441262 [Accessed: 21 August 2009].

Sussman, S.W. \& Siegal, W.S. 2003. 'Information influence in organizations: an integrated approach to knowledge adoption', Information Systems Research, 14(1), pp. 47-65.

Venkatesh, V., Morris, M.G., Davis, G.B. \& Davis, F.D. 2003. 'User acceptance of information technology: toward a unified view', MIS Quarterly, 27(3), pp. 425-478.

Whitten, J.L., Bentley, L.D. \& Dittman, K.C. 2004. Systems analysis and design methods, $6^{\text {th }}$ Edition McGraw-Hill/Irwin.

Wixom, B.H. \& Todd P.A. 2005. 'A Theoretical integration of user satisfaction and technology acceptance', Information Systems Research, 16(1), pp. 85-102.

Yu, T.F. 2001. 'Towards a capabilities perspective of the small firm', International Journal of Management Reviews, 3(3), pp. 185-197. 


\section{ANNEXURE - COMPANY CLASSIFICATION}

Below is an example of how the company's were analysed by using the four constructs and all 11 companies were classified in this manner:

\section{Company A}

Company A's main focus of business is the recording of arbitration, disciplinary and insolvency hearings as well as the transcription of these recordings and the preparation of appeal records for the courts. Advanced voice-recording devices are used with four microphones each. This allows for voice recording in larger rooms such as courtrooms.

Recordings are done in the field which needs to be transcribed. These recordings are placed on a local file and print (ftp) server, and the typist can then log into the ftp as a client to retrieve the recordings and do the transcriptions.

Company A is owned by two partners, one of whom is based in Pretoria, the other in Cape Town. It is a $50 / 50$ partnership.

Number of employees: 2 partners

Number of employees working on IT: 2

Years in operation: Almost 3 years

Types of technologies being used: Recording devices, CDs for storage of recordings, PC, photocopy machine, Skype and Internet modem

Interaction: Currently most of the communication between the employees is done through email. There is also an ftp server available whereby employees have access to download voice recordings and the storing of the transcripts of these recordings.

Environment: At this stage, the recordings are mainly done in courtroom based scenarios as this is a controlled environment with regard to voice-recording. The main operations are currently run from one of the partners' houses in Pretoria.

Affiliations: As most of the employees have worked in the same industry for quite some time, there seems to be a highly trustworthy relationship between the employees. Although there is no mention of a social network it does become evident that the employees, as well as the industry, are familiar with one another. Technology is being used to ensure interaction takes place.

Identities: Although there are a number of employees working for company A, most of them are not permanently employed. However, all potential employees have to have security checks done before they can become part of the company. Even though the employees were mentioned, most of them are not fulltime and thus only receive remuneration based on their input. 